\title{
Inactivation of Listeria monocytogenes and Salmonella Typhimurium in strawberry juice enriched with strawberry polyphenols
}

Running title: Strawberry polyphenols as natural antibacterial agent in juice

Claudia Verónica Vallejo ${ }^{1,2}$, Carlos Javier Minahk ${ }^{3}$, Graciela Celestina Rollán ${ }^{4}$ and María José Rodríguez-Vaquero ${ }^{1,2 *}$

${ }^{1}$ Institute of Microbiology, Faculty of Biochemistry, Chemistry and Pharmacy (FBQF), National University of Tucumán (UNT) and ${ }^{2}$ CONICET, Ayacucho 471, 4000, Tucumán, Argentina, ${ }^{3}$ INSIBIO, ${ }^{4}$ CERELA, Chacabuco 145, Tucumán, Argentina.

$\left(^{*}\right)$ Author to whom correspondence should be addressed: M.J. Rodríguez-Vaquero mariajo@fbqf.unt.edu.ar - Tel: 54-381-4247752 ext. 7067. Ayacucho 471, 4000, Tucumán, Argentina.

\section{ABSTRACT}

Background: To extract and identify the low molecular weight phenolic fractions (LMPFs) from Albion (LMPF-A) and Camarosa (LMPF-C) strawberry cultivars, investigate their antibacterial activities against Listeria monocytogenes and Salmonella Typhimurium cocktails in vitro and in vivo using strawberry juice as food model; and also determine the antibacterial mechanism. Results: Quercetin was identified as a principal compound in both phenolic fractions and their MIC and MBC values were around 600 and $950 \mu \mathrm{g} \mathrm{mL}^{-1}$ against $S$. Typhimurium and L. monocytogenes, respectively. The possible antibacterial activity of phenolic extracts could be related with the release of phosphate and potassium ions $\mathrm{mL}^{-1}$, the dissipation in membrane potential and the disruption of membrane integrity on L. monocytogenes; and with the inhibition of NADH oxidase activity on S. Typhimurium. Quercetin and kaempferol were the most active compounds in produce bacterial damage. The bacterial viability in strawberry juice supplemented with phenolic fractions and incubated at 37, 20 and $4{ }^{\circ} \mathrm{C}$ reduced bacterial viability, moreover with the combined treatment of phenolic fraction and the lowest temperature no viable cells were detected after 7 days incubation. Salmonella was more sensitive than

This article has been accepted for publication and undergone full peer review but has not been through the copyediting, typesetting, pagination and proofreading process which may lead to differences between this version and the Version of Record. Please cite this article as doi: $10.1002 /$ jsfa.10653 
Listeria in strawberry juice. Conclusions: This study could set the basis for the development of natural antibacterial agents could be included in natural juice or for pharmaceutical industry.

Keywords: phenolic extracts; antibacterial action mechanism; Salmonella Typhimurium; Listeria monocytogenes, strawberry juice.

\section{INTRODUCTION}

The production and export of berries have a relevant place in the economic activities of Argentine and many other countries in the world. In Argentine, during strawberries harvest a large amounts of crushed strawberries are produced and some of them are rot away every year due to the lack of processing ${ }^{1}$. The consumption of fresh strawberry juice in our country is high, and the inherent characteristics of this fruits render them susceptible to microbial contamination and potential vehicles for foodborne illness transmission ${ }^{2}$. Many studies have suggested that Listeria monocytogenes and Salmonella Typhimurium are the major causes of foodborne outbreaks ${ }^{3-4}$.

Conventionally, thermal pasteurization has been used to achieve microbial safety and preservation of fruit juices. However, temperatures used during thermal pasteurization can affect sensory properties and cause deterioration of fruit juice nutritional values ${ }^{5}$.

Application of naturally occurring antimicrobial compounds and bio-preservatives is gaining popularity for fruit juice processing as a replacement for thermal pasteurization ${ }^{6}$. Phenolic compounds represent a common constituent of the human diet, they are found in fruit, vegetables and derived products and some authors reported their beneficial properties on human health, including antiinflammatory activity, enzyme inhibition, antimicrobial activity and anti-oxidant activity ${ }^{7,8,9}$. Berries are rich in phenolic compounds and there are many reports about beneficial properties of phenolic compounds for human health, including antimicrobial activity ${ }^{7-8}$. But there are few studies about the antibacterial mechanism of phenolic extracts, especially strawberry extracts. The hypothesis of this investigation is that phenolic compounds from strawberry have antibacterial activity against $L$. monocytogenes and Salmonella Typhimurium and the antibacterial mechanism could be related with disruption on membrane integrity or inhibition of NADH oxidase activity. 
The aims of this study were 1) to extract and identify the phenolic fractions from Albion and Camarosa strawberry cultivars, 2) to determine the antibacterial activity of the phenolic fraction from strawberry cultivars against Salmonella Typhimurium and Listeria monocytogenes cocktails, 3) to investigate the possible antibacterial mechanisms of action of phenolic fractions and 4) investigate Salmonella Typhimurium and Listeria monocytogenes survival in strawberry juice as food model system.

\section{MATERIALS AND METHODS}

Extraction, identification and quantification of low molecular weight phenolic fractions (LMPFs) of strawberries.

Camarosa and Albion strawberries were selected from plantations located in northwestern Argentina, in September and November 2016, respectively. The fruits (1 kg) were washed and the LMPF Camarosa (LMPF-C) and LMPF Albion (LMPF-A) of their juice was extracted using ethyl acetate as solvent according to the technique described by Ghiselli et al. ${ }^{10}$. Total phenolic compounds in LMPFs were measured using the Folin Ciocalteu method ${ }^{11}$ and individual phenolic compounds were identified and quantified by HPLC analysis coupled to a diode array detector according to the technique described by Fanzone et al. ${ }^{12}$.

Antibacterial assay

Bacterial strain

The antibacterial activity was determined using 3-strain Salmonella Typhimurium cocktail (Typhimurium FBQF, Typhimurium H3, and Typhimurium FBQF Q5) and 3-strain Listeria monocytogenes cocktail (L. monocytogenes FBQF, monocytogenes H26 and monocytogenes FBQF A7). The bacterial strains were isolated from foods (Salmonella Typhimurium FBQF, FBQF Q5, and L. monocytogenes FBQF, FBQF A7) and obtained from culture collection of the Faculty of Biochemistry, Chemistry and Pharmacy (FBQF) of National university of Tucumán. Salmonella Typhimurium H3 and L. monocytogenes H26 were isolated from human infection and identified in The 
Public Hospital of Tucumán, Argentina. Selection of these strains and the use of bacterial cocktails are carried out to ensure that the antibacterial effect was at least against three different strains of each bacterium. The bacterial strains were grown by two successive loop transfers of individual strains incubated at $37{ }^{\circ} \mathrm{C}$ for $24 \mathrm{~h}$ in $5 \mathrm{~mL}$ BHI medium (Sigma-Aldrich). A final transfer of $0.2 \mathrm{~mL}$ was made into $50 \mathrm{~mL}$ BHI medium with incubation at $37^{\circ} \mathrm{C}$ for $18 \mathrm{~h}$. The bacterial cells were harvested by centrifugation $(4000 \times \mathrm{g}, 10 \mathrm{~min})$ at $4{ }^{\circ} \mathrm{C}$. Resulting cell pellets were washed twice in $0.1 \%(\mathrm{w} / \mathrm{v})$ peptone water (PW) and finally suspended in PW. Equal volumes of individual cultures were then mixed to obtain a 3-strain cocktail of Salmonella and Listeria of cell population of about $10^{8} \mathrm{cfu} \mathrm{mL}^{-1}$ in the inoculums.

Antibacterial activity of strawberry LMPFs and individual phenolic compounds

The antibacterial activity of strawberry LMPFs and different concentrations of pure individual phenolic compounds (10, 50 and $100 \mu \mathrm{g} \mathrm{m}^{-1}$ ) (Sigma-Aldrich) detected in LMPFs were determined using the agar diffusion test, carried out according to Rodríguez-Vaquero, et al. ${ }^{7}$ against selected bacteria. Chloramphenicol $\left(1000 \mu \mathrm{g} \mathrm{mL}^{-1}\right)$ was used as a positive control and sterile water or ethanol as negative control. After $24 \mathrm{~h}$ incubation, inhibition zones were measured to an accuracy of $0.5 \mathrm{~mm}$. For each strawberry LMPF, the minimum inhibitory concentration (MIC) and minimum bactericide concentration (MBC) were determined following the CLSI guidelines ${ }^{13}$. Briefly, Mueller-Hinton broth supplemented with serial dilutions of LMPF-C and LMPF-A was inoculated individually with bacteria 3-strain cocktail and then cultures were incubated at $37^{\circ} \mathrm{C}$ during $24 \mathrm{~h}$.

Determination of antibacterial mechanism of strawberry LMPF-C and LMPF-A

Listeria monocytogenes H26 and S. Typhimurium H3 (isolated from human infections) were selected to investigate the antibacterial mechanism of LMPFs and individual phenolic compounds. Bacterial survival and cell membrane permeabilization. L. monocytogenes H26 and S. Typhimurium H3 cultures were inoculated to obtain approximately $10^{8} \mathrm{cfu} \mathrm{mL}^{-1}$ in HEPES buffer (Sigma-Aldrich) added with strawberry LMPFs (MBC concentration) and individual phenolic compounds at concentration 10, 50 and $100 \mu \mathrm{g} \mathrm{mL} \mathrm{m}^{-1}$. Then, cells were incubated at $37^{\circ} \mathrm{C}$ during 3 hours and viability was assessed using the method of serial dilutions. Bacterial suspensions without ethanol or polyphenols 
were taken as controls. After $3 \mathrm{~h}$ incubation, the quantification of the phosphate and potassium released from bacteria was evaluated in those samples of Na-HEPES buffer containing LMPFs or individual phenolic compounds in which a reduction of around 1 log cycle was observed, using Ames's method ${ }^{14}$ and flame photometry Berry et al. ${ }^{15}$, respectively.

\section{Measurement of the transmembrane electrical potential}

The dissipation of the transmembrane electrical potential $(\Delta \Psi)$ was studied only in microorganisms in which intracellular ions were detected in supernatants, following the protocol described by Bennik et al. ${ }^{16}$. Briefly, cells were resuspended at $1.5 \times 10^{8}$ cells $\mathrm{mL}^{-1}$ in $50 \mathrm{mM}$ HEPESK buffer pH 7.4 containing $10 \mathrm{mM}$ glucose and $0.5 \mu \mathrm{M}$ of 3,3'-dipropylthiadicarbocyanine iodide (DiSC $3[5]$ ). Changes in the fluorescence were measured upon addition of LMPFs or individual phenolic compounds. An ISS PC1 spectrofluorometer was used, adjusting at $30{ }^{\circ} \mathrm{C}$, whereas the excitation and emission wavelengths were set at 622 and $674 \mathrm{~nm}$ respectively. A complete dissipation of $\Delta \Psi$ was achieved with $1 \mu \mathrm{M}$ of valinomycin. $\Delta \mathrm{pH}$ was dissipated with nigericin.

\section{Electron Microscopy}

Transmission electron microscopy was used for evaluating the L. monocytogenes H26 membrane integrity after $3 \mathrm{~h}$ incubation with strawberry LMPFs. Cell suspensions were concentrated by centrifugation (5000 rpm, $20 \mathrm{~min}$ ), and fixed with Karnovsky fixative containing 8\% (v/v) paraformaldehyde, $\mathrm{Na}_{3} \mathrm{PO}_{4}(0.1 \mathrm{M})$, pH 7.40 and $16 \%(\mathrm{w} / \mathrm{v})$ glutaraldehyde. Subsequently, samples were cuts using ultra-microtome and mounted on copper grids and contrasted with uranyl acetate solution and with lead citrate. The pellet was analyzed by transmission electron microscopy using a Zeiss EM 109 electron microscope (Carl Zeiss, Germany).

Determination of oxygen consumption and NADH oxidase activity

LMPF-C and LMPF-A $\left(1 \mu \mathrm{g} \mathrm{mL}^{-1}\right)$ were added in BHI medium the culture media was inoculated individually with L. monocytogenes H26 and S. Typhimurium H3 $\left(10^{8} \mathrm{cfu} \mathrm{mL}^{-1}\right)$; then cultures were incubated at $37^{\circ} \mathrm{C}$ for $30 \mathrm{~min}$ and the rate of cellular respiration was polarographically measured with an oxygraph-type Clark electrode and normalized to the $\mathrm{DO}_{600}$. 
The NADH oxidase activity in presence of LMPFs was determined in membrane preparations of $L$. monocytogenes H26 and S. Typhimurium H3 that were obtained as described by Evans et al. ${ }^{17}$. Measurements were carried out in the presence and the absence of $6 \mathrm{mM}$ potassium cyanide, in a total volume of $0.5 \mathrm{~mL}$ of $50 \mathrm{mM}$ phosphate buffer $(\mathrm{pH} 7.5)$ containing $0.5 \mathrm{mM}$ NADH as substrate. LMPFs were pre-incubated with membranes $\left(10 \mu \mathrm{l} \mathrm{mL}-1\right.$ proteins) for $10 \mathrm{~min}$ at $37{ }^{\circ} \mathrm{C}$. The NADH oxidase activity was measured at $570 \mathrm{~nm}$. The oxygen consumption and NADH oxidase activities of $L$. monocytogenes H26 and S. Typhimurium H3 in presence of individual phenolic compounds (100 $\mu \mathrm{g}$ $\mathrm{mL}^{-1}$ ) was only determined in those samples in which the LMPFs showed an inhibitory effect.

\section{Preparation of strawberry juice and treatments}

Strawberry juice was prepared following the protocol described by a regional company. The strawberry was provided by the National Institute of Agricultural Technology (INTA). The fruits were washed and processed until obtaining the fresh juice, then centrifuged (8000 g, 10 min, $5{ }^{\circ} \mathrm{C}$, in Heal Force centrifuge) to separate the pulp. Strawberry juice $\left(15 \pm 1^{\circ} \mathrm{Brix}, \mathrm{pH}=4.0 \pm 0.2\right)$, was pasteurized using the LTLT (low temperature-long time) method, exposing the juice at $62{ }^{\circ} \mathrm{C}$ for 30 min, then it was cooled and maintained at $4^{\circ} \mathrm{C}$. Strawberry juice was bottled under sterility conditions in $200 \mathrm{~mL}$ sterile bottles and sealed with caps. Different batches of strawberry juice (1 liter) were prepared with different treatments: a) strawberry juice without bacterial inoculation; b) strawberry juice inoculated individually with L. monocytogenes or S. Typhimurium cocktails $\left(10^{4} \mathrm{cfu} \mathrm{mL}^{-1}\right)$; c) Strawberry juice inoculated with bacteria and added with $1 \mathrm{mg}$ of LMPF-C or LMPF-A obtained from $1 \mathrm{~kg}$ of each fruit (1X), with 2 mg of LMPF-C or LMPF-A (2X) and with 3 mg of LMPF-C or LMPF-A (3X). Then, all samples were storage at different temperatures $\left(4,20\right.$ and $\left.37^{\circ} \mathrm{C}\right)$. The survivors of $L$. monocytogenes or $S$. Typhimurium were enumerated at 0 and $7 \mathrm{~d}$. The samples were serially diluted with isotonic solution and spread on Palcam agar or SSA agar. Plates were incubated for $24 \mathrm{~h}$ before enumeration.

All assays were carried out by triplicate in two independent experimental runs.

Sensory evaluation of strawberry juice enriched with LMPFs

Quantitative descriptive analysis was used to evaluate if the addition of LMPFs to strawberry juice produce negative effect in the sensory attributes of natural strawberry juice. A teach storage time, 
treated and untreated strawberry juices with and without phenolic extracts addition were subjected to a panel of testers to evaluate the sensory quality of the beverages. Ten judges, aged 25-50 years, with sensory evaluation experience were trained in descriptive evaluation of strawberry juices. The attributes evaluated were: color, odor, flavor and turbidity taste of the beverages. Evaluations were performed immediately after juices removal from storage conditions. The intensity of the attributes evaluated was quantified on an unstructured scale from 0 to 4 . Color was rated from 0 (deteriorated color) to 4 (typical color), odor from 0 (intense off-odors) to 4 (fresh) and flavor taste from0 (extremely dislike) to 4 (extremely like) and turbidity was rated from 0 (extremely dislike) to 4 (extremely like). The limit of acceptance was 2.5, indicating that score below 2.5 for any of the attributes evaluated was deemed to indicate end of shelf-life.

\section{Statistical analysis}

All experiments were repeated three times with duplicate samples. Data were analyzed by ANOVA using Minitab (Minitab Inc., PA, USA). Multiple means comparison was carried out by Duncan's multiple range tests $(p<0.05)$.

\section{RESULTS AND DISCUSSION}

The total phenolic content, the profile and quantification of individual phenolic compounds in strawberry LMPFs are shown in Table 1. The major compound found in strawberries LMPFs was quercetin. Gouveia-Figueira and Castilho ${ }^{18}$ reported that the most common flavonols in fruits and vegetables were quercetin and kaempferol.

Table 2 shows the antibacterial activities of strawberry LMPFs and pure phenolic compounds against L. monocytogenes and S. Typhimurium cocktails. Both strawberries LMPF-C and LMPF-A were effective as antibacterial agent, and quercetin and kaempferol were the most effective individual compounds. Some studies have reported the antimicrobial activity of quercetin and kaempferol rich extracts from different sources against Listeria monocytogenes and Salmonella Typhimurium 4,19,20,21. The use of the phenolic fractions of strawberry as a new natural preservative for limiting strawberry juice bacterial contamination without altering sensory or nutritional values of strawberry juice, could 
set the basis for the development of a natural antibacterial agent which could be used in pharmaceutical industry. Hence, the present study would enrich the existing knowledge regarding antibacterial activity of phenolic extracts, indicating that phenolic fractions of strawberry could be an effective natural bactericidal agent against Listeria monocytogenes and Salmonella Typhimurium to be used in food or alimentary industry". The MIC and MBC of LMPF-C and LMPF-A against $S$. Typhimurium and $L$. monocytogenes cocktails are shown in Table 3. Coincident results were reported by Lima et al. ${ }^{20}$ who reported similar values of MIC and MBC on blueberry and grape phenolic extracts rich in quercetin, $\rho$ coumaric and protocatechic acids, on antibiotic-resistant Escherichia coli and Staphylococcus aureus. Coman et al. ${ }^{22}$ reported the inhibitory effect of phenolic extracts of plums and grapes with MIC values between 7.81 to $15.63 \mathrm{mg} \mathrm{L}^{-1}$ for Bacillus cereus, E. coli, L. monocytogenes and S. aureus.

The bacterial survival after $3 \mathrm{~h}$ incubation in buffer added with strawberry LMPFs and individual phenolic compounds at concentrations of 10,50 and $100 \mu \mathrm{gL}^{-1}$ was determined. With the addition of $10 \mu \mathrm{g} \mathrm{mL} \mathrm{L}^{-1}$ of LMPFs or individual phenolic compounds there was not observed significantly difference between the numbers of viable cells observed with the control. The addition of $50 \mu \mathrm{gL}^{-1}$ of gallic, protocatechuic, $\rho$-coumaric, ferulic, caffeic, chlorogenic, ellagic acids, catechin, quercetin and kaempferol reduced $0.17 ; 0.18 ; 0.32 ; 0.27 ; 0.36 ; 0.27 ; 0.28 ; 0.30 ; 0.42$ and 0.39 log cycle the number of viable cells of L. monocytogenes H26 and 0.14; 0.25; 0.54; 0.47; 0.55; 0.34; 0.43; 0.41; 0.62; and 0.64 of $S$. Typhimurium H3, respective (Data not shown). The bacterial survival after $3 \mathrm{~h}$ incubation in buffer added with strawberry LMPFs and individual phenolic compounds at the concentration of $100 \mu \mathrm{g} \mathrm{mL}^{-1}$, the quantification of the phosphate and potassium ions released in culture supernatants, the effect on $\mathrm{NADH}$ oxidase activity and $\mathrm{O}_{2}$ consumption by L. monocytogenes H26 and S. Typhimurium H3 are shown in Table 4. All individual phenolic compounds were effective in inhibiting microbial growth against L. monocytogenes H26 and S. Typhimurium H3, reducing less than one logarithmic cycle with respect to control without treatment at the concentration of $100 \mu \mathrm{g} \mathrm{mL}$ ${ }^{1}$. The most effective phenolic compounds on L. monocytogenes H26 and S. Typhimurium H3 were $\rho$ coumaric, caffeic, chlorogenic acids, quercetin and kaempferol. S. Typhimurium H3 was more sensitive to phenolic compounds and LMPFs. LMPFs from strawberries failed to induce any release of 
these ions from S. Typhimurium H3 cells. The LMPFs from strawberries produce a low inhibition of NADH oxidase activity in L. monocytogenes H26 with respect to the control. However, strawberry LMPFs produced NADH oxidase inhibition in S. Typhimurium H3 and it was correlated with a decrease in oxygen consumption. Thus, strawberry LMPFs may prevent the growth of $S$. Typhimurium $\mathrm{H} 3$ by blocking oxygen consumption and thus inhibiting the activity of NADH oxidase, while ferulic acid, quercetin and kaempferol seem to be responsible for the strongest effect. Some studies have also shown that phenolic compounds available in berries probably play their role by increasing the efflux of ATP from pathogens and impede respiratory metabolism ${ }^{23}$.

The changes in the $\Delta \Psi$ in $L$. monocytogenes H26 and S. Typhimurium H3 in presence of both LMPFs were observed in Figure 1 (a). The $\Delta \Psi$ was dissipated upon addition of both LMPFs only in $L$. monocytogenes H26. The changes in the $\Delta \Psi$ in L. monocytogenes $\mathrm{H} 26$ in presence of individual phenolic compounds were observed in Figure 1 (b). The $\Delta \Psi$ was dissipated upon addition of both LMPFs and individual phenolic compounds to the cell suspension. Quercetin, $\rho$-coumaric acid and chlorogenic acid, produced the greatest increase of the fluorescence in L. monocytogenes H26 cell suspensions. L. monocytogenes H26 cell morphology after $3 \mathrm{~h}$ contact with LMPFs analyzed by transmission electron microscopy was observed in Figure 2. A disruption in the plasma membrane was observed in presence of strawberry LMPFs. These results suggest that the possible antibacterial mechanism of strawberry LMPFs on L. monocytogenes H26 is related to the damage of the cellular envelope. Similar results were reported by Yuan et al. ${ }^{24}$, both crude extract and eucalyptol induced membrane damage in $L$. monocytogenes. Our results are coincident with those reported by Cui et al. ${ }^{25}$ who demonstrated that phenolic fraction of clove oil affect the cell structure of $L$. monocytogenes and cause irreversible damage to the cell membrane. Other authors reported that crude phenolic extracts show better antimicrobial activity than individual compounds $27,23,8,21$. The differences between the effects caused by LMPF-C and individual phenolic compounds could be due with a synergetic effect between all phenol compounds present in the phenolic fraction. The synergic effect of individual phenolic compounds was reported by Rodríguez-Vaquero et al. ${ }^{27}$ in a previous work. Moreover, the 
antimicrobial effect of individual phenolic compounds and phenolic extracts from other sources against other pathogenic microorganisms was also reported ${ }^{28,29,8}$.

The results of LMPF-C and LMPF-A treatment of strawberry juice inoculated with $L$. monocytogenes and S. Typhimurium cocktails are shown in Figure 3a and 3b, respectively. The phenolic fractions (LMPF-C and LMPF-A) treatment in strawberry juice had a lethal effect reducing both microbial prevalence and level. The efficacy of phenolic fractions treatment varied as a function of concentration and temperature for both bacterial pathogens. A steady decrease in the surviving population of S. Typhimurium and L. monocytogenes cocktails was observed at increasing concentration (1X and $2 \mathrm{X})$. Initial inoculation population (4 $\left.\log \mathrm{cfu} \mathrm{mL}^{-1}\right)$ in the strawberry juice sample was reduced significantly $(\rho<0.05)$ due to treatment at $3 \mathrm{X}$ for 7 days at $4{ }^{\circ} \mathrm{C}$ for Salmonella and Listeria cocktails. Results indicated Listeria to be more resistant to phenolic fractions treatment compared to Salmonella in strawberry juice. Similarly, Buzrul et al. ${ }^{30}$ reported 2.5 and 3.5 logs reductions for $E$. coli and $L$. innocua, respectively in pineapple juice but the inactivation's were further increased $>1 \log$ during storage at $4{ }^{\circ} \mathrm{C}$ for $24 \mathrm{~h}$ for both bacteria. Flessa et al. ${ }^{31}$ studied survival of Listeria monocytogenes on intact and cut surface of strawberries at $4{ }^{\circ} \mathrm{C}$ and $24{ }^{\circ} \mathrm{C}$ for 7 days and reported that populations on cut surfaces remained constant at both temperatures irrespective of initial inoculum a levels throughout the storage period and concluded that $L$. monocytogenes is capable of survival but not growth on the surface of fresh intact or cut strawberries throughout the expected shelf life of the fresh fruit. Golden et al. ${ }^{32}$ studied growth of Salmonella multiserotypes in fresh cut cantaloupe, honeydew and water melons and observed no growth of Salmonella population and little or no decrease in viable populations during $24 \mathrm{~h}$ incubation at $5{ }^{\circ} \mathrm{C}$. Reports also indicated that $L$. monocytogenes, Salmonella and E. coli O157:H7 can survive during cold storage and could be recovered from apple, orange, pineapple and white grape juice concentrates and banana puree through 12 weeks of storage at $-23^{\circ} \mathrm{C}^{33}$.

Hemolysis after addition of strawberry PMPF-C and LMPF-A was similar to that of the negative control $(\rho>0.05)$, demonstrating that strawberry LMPFs are not toxic and could be safely applied to 
food. In addition, strawberry juice enriched with LMPF-C and LMPF-A (1X, 2X or 3X) do not modify the sensory attributes of untreated juice (Data not shown).

\section{CONCLUSION}

The present work reported the phenolic profile of two strawberry cultivars and their antibacterial effect against $S$. Typhimurium and L. monocytogenes in vitro and in juice. Moreover, this study is the first to elucidate their antibacterial mechanism of action against $S$. Typhimurium and L. monocytogenes, demonstrating that the antibacterial mechanism was different in both bacteria. Phenolic extracts produce disruption on membrane integrity of $L$. monocytogenes; whereas the same extracts inhibit NADH oxidase activity, avoiding the consumption of oxygen by $S$. Typhimurium. The big finding of this work was that the use of these natural extracts produces a complete inactivation of Listeria and Salmonella cocktails in strawberry juice, without sensorial attributes modifications. This study could set the basis for the development of natural antibacterial agents, important for food industry.

\section{ACKNOWLEDGEMENTS}

The present study was supported by grants from CIUNT- Argentina, Consejo Nacional de Investigaciones Científicas y Técnicas (CONICET) and Agencia Nacional de promoción científica y tecnológica (PICT 2015-1508 Préstamo BID).

\section{REFERENCES}

1. Rastogi NK, Raghavarao KSMS, Balasubramaniam VM, Niranjan K and Knoor D, Opportunities and challenges in high pressure processing of foods. Crit. Rev. Food Sci. Nutr. 47:69-112 (2007). 
2. Chen TY, Kuo SH, Chen ST and Hwang DF, Differential proteomics to explore the inhibitory effects of acidic, slightly acidic electrolyzed water and sodium hypochlorite solution on Vibrio parahaemolyticus. Food Chemistry 194(1):529-537 (2016).

3. Callejón RM, Rodríguez-Naranjo MI, Ubeda C, Hornedo-Ortega R, Garcia-Parrilla MC and Troncoso AM, Reported foodborne outbreaks due to fresh produce in the United States and European union: Trends and causes. Foodborne Pathog Dis 12(1):32-38 (2015).

4. Shen X, Sun X, Xie Q, Liu H, Zhao Y, Pan Y, Hwang C and Wu VCH, Antimicrobial effect of blueberry (Vaccinium corymbosum L.) extracts against the growth of Listeria monocytogenes and Salmonella Enteritidis. Food Control 35:159-165 (2014).

5. Sung HJ, Song WJ, Kim KP, Ryu S and Kang DH, Combination effect of ozone and heat treatments for the inactivation of Escherichia coli O157:H7, Salmonella Typhimurium, and Listeria monocytogenes in apple juice. Int. J. Food Microbiol. 171:147-153 (2014).

6. Tomadoni B, Cassani L, Moreira MR and Ponce A, Efficacy of vanillin and geraniol in reducing Escherichia coli O157:H7 on strawberry juice. LWT-Food Sci. Technol. 64:554-557 (2015).

7. Rodriguez-Vaquero MJ, Alberto MR and Manca de Nadra MC, Antibacterial effect of phenolic compounds from different wines. Food Control 18:93-101 (2007).

8. Vallejo CV, Delgado OD, Rollán GC and Rodriguez-Vaquero MJ, Control of Hanseniaspora osmophila and Starmerella bacillaris in strawberry juice using blueberry polyphenols. LWT Food Science and Technology 92:312-317 (2018).

9. Rodríguez-Vaquero MJ, Vallejo CV and Aredes-Fernandez, PA, Biological activity of phenolic compounds from Argentinean herbs infusions. The Open Conference Proceedings Journal 5:1-7 (2014).

10. Ghiselli A, Nardini M, Baldi A and Scaccini C, Antioxidant activity of different phenolic fractions separated from an Italian red wine. J Agric Food Chem 46:361-3647 (1998).

11. Singleton VL and Rossi JA, Colorimetry of total phenolics with phosphomolybdicPhosphotungstic acid reagents. J Enol Vitic 16:144-158 (1965). 
12. Fanzone M, Zamora F, Jofré V, Assof M, Gómez-Cordovés C and Peña-Neira A, Phenolic characterization of red wines from different grape varieties cultivated in Mendoza province (Argentina). J Sci Food Agric 24:154-159 (2011).

13. Clinical and laboratory Standards Institute (2006) Performance Standards for Antimicrobial Susceptibility Testing; Seventeenth Informational Supplement M100 S17 Wayne, USA.

14. Ames BN, Assay of inorganic phosphate, total phosphate and phosphatases. Methods in Enzymology 8:115-116 (1966).

15. Berry JW, Chappell DG and Barnes RB, Improved Method of Flame Photometry. Industrial and Engineering Chemistry, Analytical 18(1):19-24 (1946).

16. Bennik M, Verheul A, Abee T, Naaktgeboren-Stoffels G, Gorris L and Smid E, Interactions of nisin and pediocin PA-1 with closely related lactic acid bacteria that manifest over 100-fold differences in bacteriocin sensitivity. Appl Environ Microbiol 64:3628 (1997).

17. Evans E, Sugawara N and Haber JE, The Saccharomyces cerevisiae Msh2 mismatch repair protein localizes to recombination intermediates in vivo. Mol Cell Endocrinol 5(5):789-99 (2000).

18. Gouveia-Figueira SC and Castilho PC, Phenolic screening by HPLC-DAD-ESI/MSn and antioxidant capacity of leaves, flowers and berries of Rubus grandifolius Lowe. Industrial Crops and Products 73:28-40 (2015).

19. Wang S, Yao J, Zhou B, Yang J, Chaudry MT, Wang M, Xiao F, Li Y and Yin W, Bacteriostatic effect of quercetin as an antibiotic alternative in-vivo and its antibacterial mechanism in vitro. Journal of Food Protection. 81(1):68-78 (2018).

20. Lima MC, Paiva de Sousab C, Fernandez-Pradad C, Hareld J, Dubreuild JD and de Souzaa EL, A review of the current evidence of fruit phenolic compounds as potential antimicrobials against pathogenic bacteria. Microbial Pathogenesis 130:259-270 (2019).

21. Pal A and Tripathia A, Demonstration of bactericidal and synergistic activity of quercetin with meropenem among pathogenic carbapenem resistant Escherichia coli and Klebsiella pneumonia. Microbial Pathogenesis 143:104-120 (2020). 
22. Coman MM, Oancea AM, Verdenelli MC, Cecchini C, Bahrim GE, Orpianesi C, Cresci A and Silvi S, Polyphenol content and in vitro evaluation of antioxidant, antimicrobial and prebiotic properties of red fruit extracts. Eur. Food Res. Technol. 244:735-745 (2018).

23. Khalifa HO, Kamimoto M, Shimamoto $\mathrm{T}$ and Shimamoto $\mathrm{T}$, Antimicrobial effects of blueberry, raspberry, and strawberry aqueous extracts and their effects on virulence gene expression in Vibrio Cholerae. Phytother Res 29(11):1791-1797 (2015).

24. Yuan W, Lee HW and Yuk HG, Antimicrobial efficacy of Cinnamomum javanicum plant extract against Listeria monocytogenes and its application potential with smoked salmon. Inter J Food Microbiol 260:42-50 (2017).

25. Cui H, Zhang C, Li C and Lin L, Antimicrobial mechanism of clove oil on Listeria monocytogenes. Food Control 94:140-146 (2018).

26. Bajpai VK, Baek KH and Kang SC, Control of Salmonella in foods by using essential oils: a review. Food Res. Int. 45:722-734 (2012).

27. Rodríguez-Vaquero MJ, Aredes-Fernández PA, Manca de Nadra MC and Strasser de Saad AM, Phenolic compounds combinations on escherichia coli viability in a meat system. Journal of agricultural and food chemistry. 58: 6048-6052 (2010).

28. Vallejo CV, Aredes-Fernandez, PA, Farias ME and Rodriguez-Vaquero MJ, Biofilm inhibition of spoilage bacteria by Argentinean fruit juices with antihypertensive activity. Current Pharmaceutical Biotechnology 14(9):802-808 (2013).

29. Vallejo CV, Sosa-Mármol, Saguir FM and Rodríguez-Vaquero MJ, Antibacterial activity of grape (Vitis vinifera) pomace fatty extracts against Xanthomonas citri subsp. citri in lemons. Archives of Phytopathology and Plant Protection 52:1359-1368 (2020).

30. Buzrul S, Alpas H, Largeteau A and Demazeau G, Inactivation of Escherichia coli and Listeria innocua in kiwifruit and pineapple juices by high hydrostatic pressure. Int. J. Food Microbiology 124:275-278 (2008).

31. Flessa S, Lusk DM and Harris LJ, Survival of Listeria monocytogenes on fresh frozen strawberries. Int. J. Food Microbiology 101:255-262 (2005). 
32. Golden DA, Rhodehamel EJ and Kautter DA, Growth of Salmonella spp. in cantaloupe, watermelon, and honeydew melons. J. Food Prot. 56:194-196 (1993).

33. Oyarzabal O, Nogueira M and Gombas D, Survival of Escherichia coli O157:H7, Listeria monocytogenes, and Salmonella in juice concentrates. J. Food Prot. 66:1595-1598 (2003).

Table 1. Total phenolic compounds and phenolic profile in LMPF-A and LMPF-C.

\begin{tabular}{|c|c|c|}
\hline & LMPF-A & LMPF-C \\
\hline Total phenolic content $\left(\mu \mathrm{g}\right.$ GAE $\left.\mathrm{mg}^{-1}\right)$ & $551.93 \pm 38.63^{\mathrm{a}}$ & $589.90 \pm 41.29^{\mathrm{a}}$ \\
\hline \multicolumn{3}{|l|}{ Phenolic profile $\left(\mu \mathrm{g} \mathrm{mg}^{-1}\right)$} \\
\hline Gallic acid & $0.06 \pm 0.01^{\mathrm{a}}$ & $0.03 \pm 0.01^{\mathrm{b}}$ \\
\hline Protocatechuic acid & $0.38 \pm 0.03^{\mathrm{a}}$ & $0.36 \pm 0.02^{\mathrm{b}}$ \\
\hline Trans-caffeic acid & $12.14 \pm 0.95^{\mathrm{a}}$ & $2.56 \pm 0.18^{\mathrm{b}}$ \\
\hline Ester of $\rho$-coumaric acid & $1.44 \pm 0.10^{\mathrm{a}}$ & $0.68 \pm 0.05^{\mathrm{b}}$ \\
\hline Trans- $\rho$-coumaric acid & $2.76 \pm 0.19^{\mathrm{a}}$ & $1.67 \pm 0.12^{\mathrm{b}}$ \\
\hline Ferulic acid & $0.99 \pm 0.01^{\mathrm{a}}$ & $0.70 \pm 0.05^{\mathrm{b}}$ \\
\hline Ellagic acid & $10.64 \pm 0.74^{\mathrm{a}}$ & $4.51 \pm 0.31^{\mathrm{b}}$ \\
\hline$(+)$-catechic & $11.90 \pm 0.83^{\mathrm{a}}$ & $9.63 \pm 0.67^{b}$ \\
\hline (-)-epicatechic & $4.03 \pm 0.28^{\mathrm{a}}$ & $3.37 \pm 0.23^{b}$ \\
\hline Procyanidin & $10.44 \pm 0.73^{\mathrm{a}}$ & $3.78 \pm 0.26^{\mathrm{b}}$ \\
\hline Kaempferol-3-galactoside & $5.84 \pm 0.41^{\mathrm{a}}$ & $8.74 \pm 0.61^{b}$ \\
\hline Kaempferol-3-glucoside & $5.44 \pm 0.38^{a}$ & $6.30 \pm 0.44^{\mathrm{a}}$ \\
\hline Quercetin-3-glucuronide & $10.24 \pm 0.72^{\mathrm{a}}$ & $6.75 \pm 0.47^{\mathrm{a}}$ \\
\hline Quercetin-3-galactoside & $10.12 \pm 0.71^{\mathrm{a}}$ & $3.82 \pm 0.27^{b}$ \\
\hline Quercetin-3-glucoside & $20.44 \pm 1.43^{\mathrm{a}}$ & $23.07 \pm 1.61^{\mathrm{a}}$ \\
\hline Laricitrin-3-galactoside & $2.09 \pm 0.15^{\mathrm{a}}$ & $2.29 \pm 0.16^{\mathrm{a}}$ \\
\hline Laricitrin-3-glucoside & $3.92 \pm 0.20^{\mathrm{a}}$ & $4.60 \pm 0.32^{b}$ \\
\hline
\end{tabular}


Isoramnetine-3-glucoside $3.61 \pm 0.18^{\mathrm{a}} \quad 3.74 \pm 0.26^{\mathrm{a}}$

Different letters in the same row show significant differences $(p<0.05)$.

Table 2. Antibacterial activities of strawberry LMPFs and individual phenolic compounds.

\begin{tabular}{lcc}
\hline & L. monocytogenes cocktail & S. Typhimurium cocktail \\
\hline LMPF-C & ++ & ++ \\
LMPF-A & ++ & ++ \\
\cline { 2 - 3 }
\end{tabular}

Phenolic compound concentration $\left(\mu \mathrm{g} \mathrm{mL}^{-1}\right)$

\begin{tabular}{|c|c|c|c|c|c|c|}
\hline & 10 & 50 & 100 & 10 & 50 & 100 \\
\hline Gallic acid & W & + & + & W & + & ++ \\
\hline Protocatechuic acid & $\mathrm{W}$ & + & + & W & + & ++ \\
\hline$\rho$-coumaric acid & W & + & + & + & ++ & +++ \\
\hline Ferulic acid & W & + & + & $\mathrm{W}$ & + & ++ \\
\hline Caffeic acid & W & + & ++ & + & ++ & +++ \\
\hline Chlorogenic acid & W & + & ++ & + & ++ & +++ \\
\hline Ellagic acid & $\mathrm{w}$ & + & + & $\mathrm{W}$ & + & ++ \\
\hline Catechin & $\mathrm{W}$ & + & + & $\mathrm{W}$ & + & ++ \\
\hline Quercetin & + & ++ & +++ & + & ++ & +++ \\
\hline Kaempferol & + & ++ & +++ & + & ++ & +++ \\
\hline Control (+) & \multicolumn{3}{|c|}{+++} & \multicolumn{3}{|c|}{+++} \\
\hline Control (-) & \multicolumn{3}{|c|}{ - } & \multicolumn{3}{|c|}{ - } \\
\hline
\end{tabular}

Antibacterial activity: Inhibition zone $<1 \mathrm{~mm}$, nil (-); Inhibition zone 1-5 mm, weak (w); Inhibition zone 6-11 mm, moderate $(+)$; Inhibition zone 12-19 mm, high $(++)$; inhibition zone $>19 \mathrm{~mm}$, strong $(+++)$.

Table 3. MIC and MBC of LMPF-C and LMPF-A against L. monocytogenes and S. Typhimurium cocktails

\begin{tabular}{ccccc}
\hline & \multicolumn{2}{c}{ LMPF-C } & \multicolumn{2}{c}{ LMPF-A } \\
\cline { 2 - 5 } & MIC $^{*}$ & MBC* & MIC* & MBC* $^{*}$ \\
\hline L. monocytogenes cocktail & $650 \pm 20.00^{\mathrm{a}}$ & $850 \pm 40.00^{\mathrm{a}}$ & $700 \pm 25.00^{\mathrm{a}}$ & $950 \pm 45.00^{\mathrm{a}}$ \\
S. Typhimurium cocktail & $600 \pm 18.00^{\mathrm{b}}$ & $750 \pm 32.00^{\mathrm{b}}$ & $660 \pm 20.00^{\mathrm{b}}$ & $800 \pm 30.00^{\mathrm{b}}$ \\
\hline
\end{tabular}

* $\mu \mathrm{g} \mathrm{mL} \mathrm{L}^{-1}$ of phenolic extract. Different letters in the same column show significant differences $(p<0.05)$ 
Table 4. Phosphate and potassium concentration released in culture supernatants, inhibition of NADH oxidase activity and oxygen consumption by L. monocytogenes H26 and $S$. Typhimurium H3 after $3 \mathrm{~h}$ of incubation in media supplemented with LMPFs and individual phenolic compounds.

\begin{tabular}{|c|c|c|c|c|c|c|c|c|c|c|}
\hline \multirow[b]{2}{*}{ Samples } & \multirow[b]{2}{*}{ Log cfu mL $L^{-1}$} & \multicolumn{4}{|c|}{ L. monocytogenes H26 } & \multirow[b]{2}{*}{ Log cfu mL ${ }^{-1}$} & \multirow[b]{2}{*}{$\begin{array}{l}\text { Potassium } \\
\text { release } \\
\left(\mu \mathrm{g} \mathrm{mL} \mathbf{~ m}^{-1}\right)\end{array}$} & \multicolumn{3}{|c|}{ S. Typhimurium H3 } \\
\hline & & $\begin{array}{l}\text { Potassium } \\
\text { release } \\
\left(\mu \mathrm{g} \mathrm{mL} L^{-1}\right)\end{array}$ & $\begin{array}{c}\text { Phosphate } \\
\text { release } \\
\left.(\mu \mathrm{g} \mathrm{mL})^{-1}\right)\end{array}$ & $\begin{array}{c}\text { NADH } \\
\text { inhibition } \\
(\%)\end{array}$ & $\begin{array}{c}\mathrm{O}_{2} \\
\text { consumption } \\
(\%)\end{array}$ & & & $\begin{array}{l}\text { Phosphate } \\
\text { release } \\
\left(\mu \mathrm{g} \mathrm{mL} L^{-1}\right)\end{array}$ & $\begin{array}{c}\text { NADH inhibition } \\
(\%)\end{array}$ & $\begin{array}{c}\mathrm{O}_{2} \text { consumption } \\
(\%)\end{array}$ \\
\hline Control & $7.17 \pm 0.36^{\mathrm{a}}$ & & & & & $7.04 \pm 0.35^{\mathrm{a}}$ & & & & \\
\hline LMPF-C & $6.63 \pm 0.33^{\mathrm{a}, \mathrm{b}}$ & $17.10 \pm 0.85^{\mathrm{a}}$ & $12.98 \pm 0.65^{\mathrm{a}}$ & $10.00 \pm 0.49^{\mathrm{a}}$ & $75.00 \pm 3.80^{\mathrm{a}}$ & $6.19 \pm 0.30^{\mathrm{b}}$ & $N d$ & $N d$ & $80.00 \pm 3.98^{\mathrm{a}}$ & $6.00 \pm 0.29^{\mathrm{a}}$ \\
\hline LMPF-A & $6.52 \pm 0.32^{\mathrm{b}, \mathrm{c}}$ & $15.70 \pm 0.76^{\mathrm{a}, \mathrm{b}}$ & $15.87 \pm 0.79^{b}$ & $13.00 \pm 0.65^{b}$ & $70.00 \pm 3.50^{\mathrm{a}}$ & $6.12 \pm 0.31^{\mathrm{b}}$ & $N d$ & $N d$ & $85.00 \pm 4.22^{\mathrm{a}}$ & $5.00 \pm 0.16^{\mathrm{b}}$ \\
\hline Gallic acid & $6.69 \pm 0.33^{\mathrm{c}, \mathrm{a}}$ & $6.50 \pm 0.32^{\mathrm{c}}$ & $5.77 \pm 0.29^{c}$ & $n d$ & $N d$ & $6.40 \pm 0.32^{\mathrm{a}, \mathrm{b}}$ & Nd & $N d$ & $51.67 \pm 2.58^{b}$ & $50.35 \pm 2.52^{\mathrm{c}}$ \\
\hline Protocatechuic acid & $6.56 \pm 0.32^{\mathrm{b}, \mathrm{c}}$ & $7.10 \pm 0.35^{\mathrm{c}, \mathrm{d}}$ & $6.55 \pm 0.33^{\mathrm{d}}$ & $N d$ & $N d$ & $6.37 \pm 0.32^{\mathrm{a}, \mathrm{b}}$ & $N d$ & $N d$ & $50.31 \pm 2.52^{\mathrm{b}}$ & $24.00 \pm 1.23^{\mathrm{d}}$ \\
\hline$\rho$-coumaric acid & $6.51 \pm 0.32^{\mathrm{c}}$ & $7.30 \pm 0.36^{\mathrm{d}, \mathrm{e}}$ & $6.45 \pm 0.19^{\mathrm{d}}$ & $N d$ & $N d$ & $6.08 \pm 0.30^{\mathrm{b}}$ & $N d$ & $N d$ & $32.76 \pm 1.64^{\mathrm{c}}$ & $31.09 \pm 1.57^{\mathrm{e}}$ \\
\hline Ferulic acid & $6.49 \pm 0.31^{c}$ & $7.55 \pm 0.38^{\mathrm{d}, \mathrm{f}}$ & $7.09 \pm 0.35^{\mathrm{d}, \mathrm{e}}$ & $N d$ & $N d$ & $6.03 \pm 0.29^{b}$ & $N d$ & $N d$ & $56.67 \pm 2.83^{b}$ & $40.73 \pm 2.05^{f}$ \\
\hline Caffeic acid & $6.37 \pm 0.30^{\mathrm{c,d}}$ & $7.23 \pm 0.36^{\mathrm{d}, \mathrm{e}, \mathrm{f}}$ & $6.98 \pm 0.35^{\mathrm{e}}$ & $N d$ & $N d$ & $5.93 \pm 0.28^{b}$ & $N d$ & $N d$ & $36.21 \pm 1.81^{\mathrm{c,d}}$ & $25.76 \pm 1.29^{\mathrm{d}}$ \\
\hline Chlorogenic acid & $6.48 \pm 0.32^{\mathrm{a}, \mathrm{b}, \mathrm{c}}$ & $7.11 \pm 0.35^{\mathrm{d}}$ & $7.01 \pm 0.37^{\mathrm{d}, \mathrm{e}}$ & $N d$ & $N d$ & $5.89 \pm 0.27^{b}$ & $N d$ & $N d$ & $50.00 \pm 2.48^{\mathrm{b}}$ & $45.70 \pm 2.29^{c}$ \\
\hline Ellagic acid & $6.51 \pm 0.33^{c}$ & $7.24 \pm 0.36^{\mathrm{d}}$ & $6.99 \pm 0.36^{\mathrm{d}, \mathrm{e}}$ & $N d$ & $N d$ & $6.10 \pm 0.30^{\mathrm{b}}$ & $N d$ & $N d$ & $48.00 \pm 2.33^{\mathrm{b}, \mathrm{e}}$ & $42.00 \pm 2.13^{f}$ \\
\hline Catechin & $6.53 \pm 0.34^{\mathrm{a}, \mathrm{c}, \mathrm{d}}$ & $7.97 \pm 0.40^{\mathrm{d}, \mathrm{g}}$ & $6.59 \pm 0.33^{\mathrm{d}, \mathrm{e}}$ & $N d$ & $N d$ & $6.11 \pm 0.31^{\mathrm{b}}$ & $N d$ & $N d$ & $53.00 \pm 2.76^{\mathrm{b}}$ & $39.00 \pm 1.97^{f}$ \\
\hline Quercetin & $6.36 \pm 0.31^{\mathrm{b}, \mathrm{d}}$ & $9.26 \pm 0.46^{\mathrm{h}}$ & $8.60 \pm 0.43^{f}$ & $N d$ & $N d$ & $5.75 \pm 0.28^{b}$ & $N d$ & $N d$ & $63.33 \pm 3.17^{f}$ & $48.12 \pm 0.42^{\mathrm{c}}$ \\
\hline Kaempferol & $6.42 \pm 0.32^{\mathrm{c}, \mathrm{d}}$ & $9.31 \pm 0.46^{\mathrm{h}}$ & $9.08 \pm 0.45^{\mathrm{f}, \mathrm{g}}$ & $N d$ & $N d$ & $5.81 \pm 0.29^{b}$ & $N d$ & $N d$ & $58.00 \pm 2.99^{b}$ & $45.11 \pm 2.27^{c}$ \\
\hline Positive control & $100.00 \pm 6.21^{\mathrm{e}}$ & $100.00 \pm 6.21^{\mathrm{i}}$ & $100.00 \pm 6.21^{\mathrm{h}}$ & $100.00 \pm 6.21^{\mathrm{c}}$ & $N d$ & $100.00 \pm 6.21^{\mathrm{c}}$ & + & + & $100.00 \pm 6.21^{\mathrm{g}}$ & $N d$ \\
\hline Negative control & $N d$ & $N d$ & $N d$ & $N d$ & $100.00 \pm 6.21^{b}$ & $N d$ & $N d$ & $N d$ & $N d$ & $100.00 \pm 6.21^{\mathrm{g}}$ \\
\hline
\end{tabular}

Different letters in the same column show significant differences $(p<0.05)$

nd: no determine.

Nd: No detected 


\section{Figure legends}

Figure 1. Membrane potential of glucose-energized of L. monocytogenes H26 and S. Typhimurium H3 after addition of LMPF-A ( $\square$ ) $\square$ ) and LMPF-C @ )Q ) strawberry cultivars, respectively (a). Effect of individual phenolic compounds: gallic $(\square)$, chlorogenic $(\bullet) \rho$-coumaric $(\diamond)$, protocatechuic $(\bigcirc)$, ferulic $(*)$, caffeic $(\times)$, ellagic acid $(\diamond)$, catechin $(O)$ and kaempferol $(\square)$ and quercetin $(\Delta)$ on the membrane potential of glucose-energized L. monocytogenes H26 (b). Cells treated with $\mathrm{DiSC}_{3}[5]$ and suspended in $10 \mathrm{mM}$ glucose were treated for indicated times with $1 \mu \mathrm{M}$ nigericin, $1 \mu \mathrm{M}$ valinomycin $(\Delta)$ and negative control $(\boldsymbol{\Delta})$. Each value in the figure is representative of at least 4 independent experiments.

Figure 2. Electron microscopy analysis of effect of LMPFs on L. monocytogenes H26 with a magnification of 12800x of in control buffer (a) and buffer added with LMPF-A (b) and LMPF-C (c) strawberry cultivars, after 3h of contact.

Figure 3. Survival of L. monocytogenes (a) and S. Typhimurium (b) cocktails in strawberry juice control ( $\square$ ) and strawberry juice supplemented with LMPF-C and LMPF-A 1x ( $\square$ ), 2x ( $\square$ ) or 3x ( $\square$ ), after 7 days incubation at different temperatures (37, 20 and $\left.4^{\circ} \mathrm{C}\right)$. 

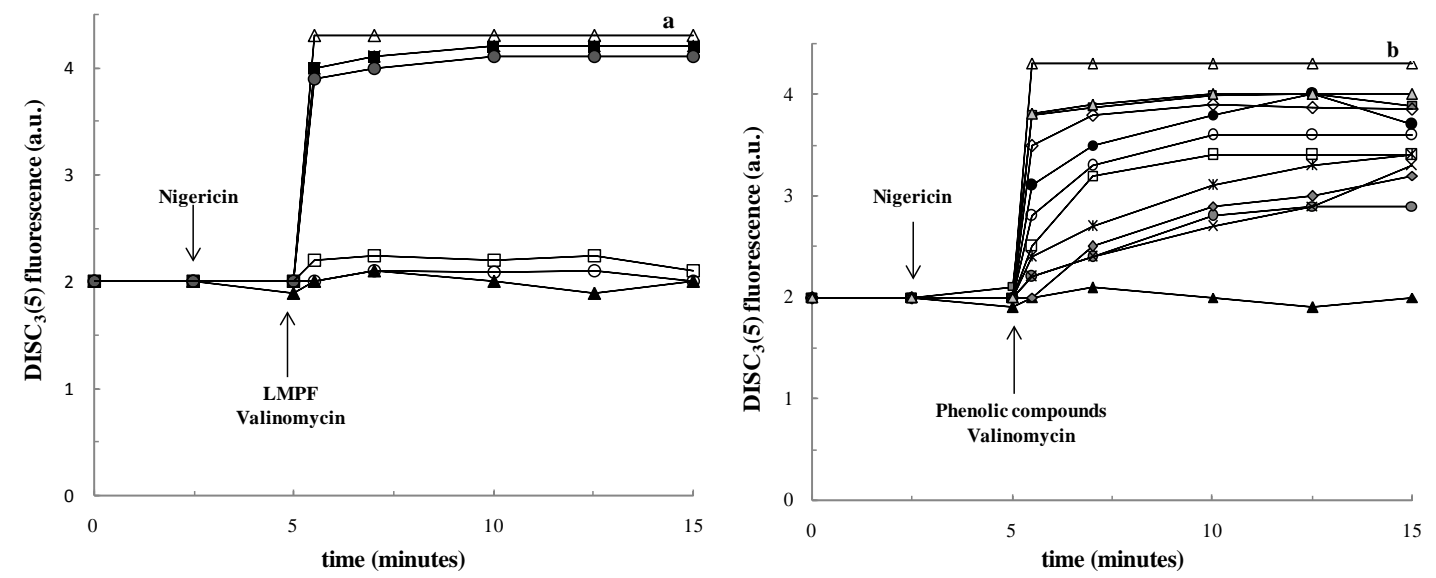

Figure 1

a

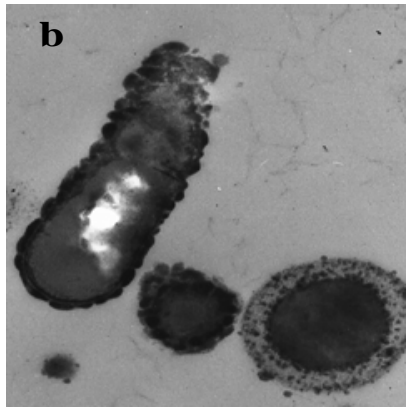

C

Figure 2

This article is protected by copyright. All rights reserved. 

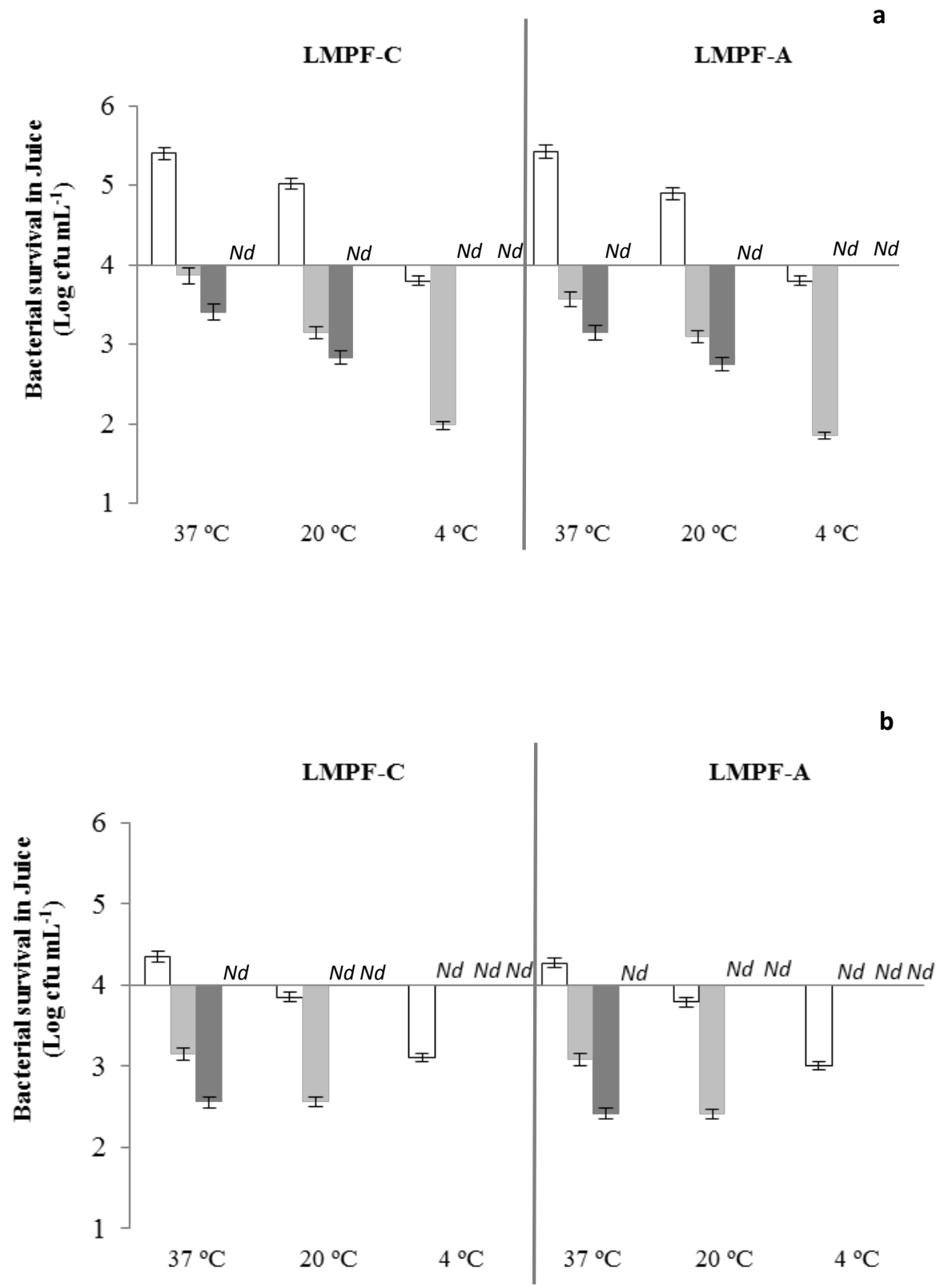

Figure 3 